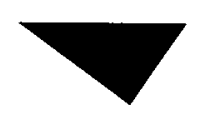

\title{
Etnia, Imprensa e Essencialismo
}

\author{
André Augusto Brandĩo* \\ Universidade Federal Fluminense
}

Este arrigo pretende discurir as imagens soctais produridas acerea (to negro na sociedade brasileira. e as formas calturais que este grupo émico constroit.

A base de pesquisa milisada foram os artigos da coluna "Black" do Jomal Folha de Sĩo Paulo, publicados entre outubro de $199+\mathrm{te}$ desembro de 1998.

foi possivel verificar que estereotipos e essencialismos produsides sobre os negros podem ser uscidos positivamente por este srapo como estratégin para assegurar meios especificos de sobreviviencia economica.
This article intonds to discuss the social inages related to black people in brasilian society and the cultural forms that this cthnic shoup builds.

This research was based on articles of the "Black" apright section of Follha de Säo Parblo Newspaper published beneen october; 1994 and december; 1998.

If was possible to verify that estereonyes and essencialismis created about black people am be used positively by them as a strategy. to assure specific means of eronomiral survite.

*O autor é professor da Escola de Scrviço Social da UFF, pesquisador do PENESB-UFF; mestre em Sociologia pela UFRJ e doutorando $\mathrm{cm}$ Ciencias Sociais pela UERJ. 


\section{"Não abro mão da mitologia negra Pra dizer eu não parefo com você." \\ O Rappa}

Nas estações de metrô do Rio de Janeiro, encontramos uma interessante propaganda institucional. Em vários painéis, a companhia gestora tenta convencer os passageiros que o metrô é o mais rápido meio de transporte coletivo da cidade. Um dos painéis, mostra a foto de um homem branco, de presumíveis 35 anos, vestindo camisa social e gravata. Este pergunta: "Sabe porque só ando de metrô ?" E responde: "porque tempo é dinheiro". Outro painel, poucos metros adiante, mostra a foto de um homem negro também com

112 presumíveis 35 anos, vestindo uma camisa "sport" em tecido jeans. Este faz a mesma pergunta que o homem branco, e responde: "porque tomar café da manhã com pressa faz mal".

O homem branco, é associado a uma profissão de "colarinho branco" ou de comando, e com sua resposta, que remete a poupar tempo para ganhar dinheiro, sugere-nos a idéia de ser um executivo. O homem negro, que não esta vestido com a roupagem típica de quem trabalha em uma profissão qualificada ou de maior prestígio social, pensa somente em tomar um café da manhã sem sobressaltos para chegar - cedo - no trabalho; sugere-nos uma idéia profissional vaga, um comerciário ou um operário industrial. De qualquer forma a mensagem parece clara: o negro trabalha, o branco ganha dinheiro.

Esta essencialização de grupos étnicos como portadores inexoráveis de características que se materializam em comportamentos, culturas, e até mesmo lugares na estrutura produtiva, é alvo das discussões empreendidas por Bhabha (1998). Neste autor que se coloca no campo da crítica "pós-colonial", importa caracterizar os processos a partir do qual a razão ocidental classificou de forma essencial os povos coloniais (classificação que se reflete ainda hoje nas relações que se estabelecem entre os países ocidentais e os países de passado colonial e entre os primeiros e as minorias étnicas lá existentes). Esta essencialização aparece no pensamento ocidental como "narrativas de subjetividades originárias" (Bhabha,1998: 19). Na perspectiva de Bhabha (1998), as novas identidades pós-coloniais para se formarem precisam contestá-las e destruí-las.

Toda a argumentação de Bhabha (1998) segue na direção de afirmar que as diferenças entre as culturas não são o "reflexo de traços culturais ou étnicos preestabelecidos inscritos na lápide fixa da tradição", ou que exista algo como uma "identidade original ou tradição 'recebida' "(Bhabha,1998: 20-21).

Ainda que os "povos subordinados" carreguem como necessidade política a afirmação de tradições culturais e históricas, estas inici- 
ativas guardam o perigo de construir identidades fixas e cristalizadas como culturas coloniais, com a celebração do passado e a perspectiva de homogeneização do presente.

Na posição de Bhabha (1998), a essencialização de culturas e etnias é parte da noção liberal de "multiculturalismo" ou "diversidade cultural". Mais precisamente, a noção de diversidade consiste em uma:

“... retórica radical da separação de culturas totalizadas que existem intocadas pela intertextualidade de seus locais históricos, protegidas na utopia de uma memória mítica de uma identidade coletiva única." (Bhabha, 1998: 63)

A proposta de Bhabha (1998), portanto, consiste na conceituação de cultura internacional como algo fundado no "hibridismo" das formas culturais e não no multiculturalismo que toma o não ocidental como exótico. Isto porque, a diversidade cultural lê o "sujeito colonial" no campo do imagético, do fantasioso, enfim de forma estereotipada.'

Se as diferenças não são o efeito de essenciais identidades totalizantes fundadas no passado, quais são suas demarcações? São as performances, a negociação dos espaços culturais, o retraçar das fronteiras. Nesta perspectiva pós-colonial aparece como ponto político fundamental a luta contra a fixação essencialista do campo étnico.

Mas retornemos aos painéis do metrô do Rio de Janeiro e seu essencialismo. Estes são somente uma amostra da velada e comple$x a$ quase segmentação racial do mercado de trabalho, que sobredetermina as diferenças sociais e econômicas entre brancos e negros ${ }^{2}$ no Brasil, o que já foi demostrado em inúmeros estudos.

Oliveira et al (1985) trabalha com dados oriundos da Pesquisa Nacional por Amostra de Domicílios (PNAD) ${ }^{3}$ - IBGE - 1976, para concluir que "a raça permanece um princípio classificatório importante na sociedade brasileira" (Oliveira et al, 1985: 79), na medida em que a posição sócio-econômica dos afro-descendentes ("pretos" e "pardos" na classificação do IBGE), apresenta sempre déficit em relação à população "branca", seja na escolaridade, seja na remuneração, seja no acesso às profissões de maior prestígio social.

Lovell (1995) trabalha com dados censitários de 1960 e 1980 para demostrar que apesar do Brasil ter verificado entre 1956 e 1984 um crescimento econômico médio de aproximadamente $7 \%$ ao ano; este período não foi suficiente para dissolver as desigualdades sócio-econômicas e espaciais existentes entre os brancos e a população afro-descendente no que tange principalmente a: lugar de moradia, anos de educação formal, profissão e renda; o que confirma a existência de práticas de exclusão na sociedade brasileira con- 
temporânea. A autora chama ainda a atenção para a relação direta entre emprego/renda e bem-estar individual, o que aponta, considerando a diferença entre os dois grupos raciais, o peso que esta variável possui na demarcação das possibilidades de acesso em geral aos bens materiais e culturais.

Sant'Anna e Paixão (1997) nos dão indicações, ainda que gerais sobre os anos 1990. Os autores apresentam dados da PNAD-1987 que são extremamente elucidativos. Da população ocupada em 1987, $38,85 \%$ dos pretos ganhavam até 1 salário mínimo, nos pardos o percentual chega a $35,1 \%$ e nos brancos $18,6 \%$. No que tange a faixa 114 superior a 10 salários mínimos, somente $1,2 \%$ dos pretos e $2,5 \%$ dos pardos a alcançavam, enquanto entre os brancos, percebiam salários nesta faixa $9,3 \%$. Neste mesmo ano, $47 \%$ dos pretos e $51 \%$ dos pardos trabalhavam sem carteira assinada, enquanto os brancos nesta condição eqüivalem a $35 \%$. A taxa de analfabetismo entre pretos e pardos maiores de 25 anos de idade era de respectivamente $35,2 \%$ e $33,6 \%$; entre os brancos era de $15 \%$. A conclusão inequívoca aqui é que a raça é ainda uma variável fundamental para alicerçar estudos que pretendam compreender a lógica da exclusão social no Brasil.

Para além destes elementos macro econômicos que guardam enorme importância para que possamos pensar os quadros gerais em que se processam as relações raciais no Brasil; é necessário compreender quais as estratégias que os negros desenvolvem frente a exclusão do mercado de trabalho. Esta é uma das preocupações que aparecem em uma série de artigos de Sansone. ${ }^{4}$

Elaborando discussões sobre a "cultura negra" em Amsterdam, em bairros pobres da Região Metropolitana de Salvador, ou comparando ambas; Sansone tem demostrado que a partir dos anos 1980 podemos reconhecer no Brasil o uso mais intenso de símbolos que se vinculam à uma origem afirmada como africana, com forte presença no campo da mídia e do lazer. Essa constatação suscita inúmeras discussões e inicialmente nos coloca no âmbito do que poderíamos denominar. "cultura negra". Em Sansone (1995 e 1999) encontramos uma interessante definição. A "cultura negra" seria uma subcultura mais específica de uma cultura africana-americana maior; localizada em sociedades nas quais a cor ou a descendência de indivíduos de determinada cor, funciona como um elemento importante em processos sociais de diferenciação e discriminação de grupos ou pessoas. Haveria, como elemento importante de "coesão" da cultura negra, o passado escravo. Este passado também remete à África que segundo Sansone (1995 e 1999) é usada como um "banco de símbolos". No entanto, a forma através das quais estes símbolos 
são sacados, depende das condições sócio-econômicas locais e principalmente do formato que ganham as relações raciais em países diferentes.

Um ponto importante apontado por Sansone (1995 e 1999) é a grande interdependência entre a cultura negra e a modernidade urbana no Ocidente. Esta seria a explicação para a difícil expressão comunitária dos negros. Ou seja, os negros através da afirmação étnica têm construído uma "nova etnicidade" que não se cristaliza em uma cultura sistemática ou uma identidade coletiva, e que via de regra não impulsiona movimentos de protesto nos moldes políticos dos movimentos de trabalhadores, por exemplo. Assim, em sua "rebeldia", os negros jovens expressam sua diferença relativa; principalmente através da desinibição com a negritude (e afirmação desta: o cabelo, a roupa, a música). Neste sentido, uma característica recorrente desta cultura negra se encontra no uso do corpo e na "manipulação da aparência física" (Sansone, 1995: 66).

Há também características que são semelhantes nas várias "culturas negras", ou seja nos vários países da diáspora negra, onde estes. como minoria étnica ou não, produzem ou rearticulam sincreticamente formas culturais. Estas características comuns podem suscitar diferentes explicações. Se os afrocentristas acreditam num vínculo primário dos negros com umas cultura africana ancestral; é possível reconhecer a existência de outros caminhos, ligados às históricas trocas internacionais através do Atlântico Negro., como afirma Gilroy (1995) - em um claro movimento de crítica ao "absolutismo étnico" - a cultura negra é o resultado, entre outras coisas, dos

"... Blacks dispersed within the structures of feeling, producing. communicating and remembering that I have heuristically called the Black Atlantic." (Gilroy, 1995: 3).

O barco constitui uma imagem importante para representar esta comunicação atlântica de projetos, idéias, movimentos, elementos culturais, etc.

Ainda sobre esta questão Sansone (1999) afirma a existência de um elemento de homogeneização das experiências, contida no passado de escravidão e deportação, no racismo ainda presente (embora mais sutil). Outro ponto de ligação entre culturas negras no mundo vem do fato de que os negros estão concentrados sempre na base da pirâmide social dos países multirraciais em que vivem. Neste sentido Pierucci (1999) fala de proximidade ancorada em formas parecidas de exclusão:

".... a possibilidade de uma identificação comum está no fato de que as comunidades negras, por mais diferentes que se saibam em 
recursos culturais e em passado histórico, têm sido, não obstante, olhadas e tratadas pela cultura dominante do Ocidente como 'a mesma coisa'. Está na experiência da discriminação-com-exclusão. Discriminação racial com exclusão social."

(Pierucci , 1999: 158)

No que tange à especificidade da cultura negra que se desenvolve no Brasil, há um forte condicionamento da colonização Ibérica. Aqui, portanto, as relações raciais comportam uma miscigenação muito maior da que a ocorrida nos países de colonização inglesa e mesmo francesa ou holandesa. Desta miscigenação resulta um "continuum de cor" que é significativo para a compreensão de nossas relações raciais. Outra especificidade vinculada à colonização Ibérica é a igreja católica romana que desde o início do escravismo colonial obrigava os negros recém-chegados à conversão e os aceitava como "povo de deus". Os negros, por sua vez, reinterpretaram o catolicismo e produziram novas linguagens religiosas híbridas (esta tradição de hibridismo religioso é hoje classificada como "impura" por alguns segmentos negros - esta dialética pureza / manipulação é muito comum nas formas que assume a cultura negra; a pureza como o que está próximo das raízes africanas e a manipulação como o sincretismo que pode articular tanto elementos da cultura branca, quanto de uma "modernidade geral").

A permeabilidade religiosa, a miscigenação elevada e a conseqüente não polarização das relações raciais gerou uma "heterofobia" (Sansone, 1999), ou seja uma negação generalizada da diversidade e differença cultural e uma afirmação forte da nacionalidade brasileira.

- Neste ponto vale retomar o texto de Renan $(1990)^{6}$, que nos quadros de uma postura anti-essencialista, que recusa qualquer critério de pertencimento nacional objetivo, toma a nação como sendo formada por uma seqüência histórica de fatos em maior ou menor medida aleatórios, de conquistas bélicas e de divisões territoriais casuístas. Neste processo de construção da nação afirma que os indivíduos não somente devem ter algo em comum, mas que, fundamentalmente, devem esquecer o passado. Isto significa esquecer as lutas, os massacres, os genocídios e a supressão forçada das diferenças culturais, que representaram o domínio final de um grupo (que para Renan seria étnico) que terá o poder de nomear a nação. A afirmação da nacionalidade brasileira pressupõe que negros e índios realmente esqueçam muitas coisas.

Mas qual a relação entre a cultura negra no Brasil e a "exclusão" deste grupo do mercado de trabalho ?

'Em pesquisa realizada na Região Metropolitana de Salvador, mas 
em nossa opinião passível de generalização - desde que cuidadosa para o restante das áreas metropolitanas do Brasil, Sansone (1999) encontra um contingente muito elevado de jovens negros (até 25 anos) em situação de desemprego, embora estes possuíssem escolaridade superior a de seus país (que não enfrentavam uma situação tão drástica no mercado de trabalho). Este percentual de desemprego deve ser relativizado, a partir de elementos muito significativos. Ou seja, os jovens que atuavam em atividades informais (biscates) preferiam se denominar desempregados, pois esta situação thes parecia menos estigmatizante do que o trabalho manual desqualificado e mal remunerado.

Estas representações se vinculam, entre outras coisas, a uma generalização da escola básica e da crença na ascensão social via educação ${ }^{7}$. Como tal ascensão não se verifica de fato o descontentamento desta geração com suas condições sócio-econômicas, é muito maior que o da geração anterior. Neste descontentamento estão incluídas as possibilidades de trabalho que a economia reserva para serem disputados por indivíduos com pequena (ou nenhuma) qualificação para o mercado de trabalho. Assim, ocorre o que Sansone (1999) denomina "auto-exclusão" do mercado de trabalho.

Estes jovens recusam os trabalhos que avaliam como "indignos" e esperam trabalhos que consideram "dignos" e "adequados". Desta opção derivam várias situações de busca do mercado informal, do crime, do uso do corpo (via prostituição ou não), por expedientes ligados ao embelezamento (penteados e tranças "étnicas") ou via arte (principalmente a musica e a dança).

Esta auto-exclusão pode estar vinculada com uma perspectiva de antagonismo em relação aos brancos, negando trabalhos impostos aos negros ou de integração à estes pela via da mídia e do lazer. Aqui vale retomar uma idéia interessante que aparece em Sansone (1995) acerca da existência de áreas duras e moles nas relações raciais no Brasil. As primeiras ligadas ao mercado de trabalho, aos contatos sentimentais e amorosos, e aos contatos com a polícia; onde o preconceito ainda se impõe com força. Nas segundas estão o lazer os contatos religiosos; estas as áreas moles são aquelas onde o fato de ser negro não impõe obstáculos. Mas haveria também um domínio que Sansone (1995) denomina "espaço negro" onde o fato de ser negro pode ser uma vantagem e mesmo significar prestígio. Neste domínio Sansone (1995) alenca os blocos afro, a batucada, a capoeira e o terreiro, mas poderíamos acrescentar (pensando no conjunto das áreas metropolitanas brasileiras) no rap, no embelezamento "étnico", etc. 
Este último domínio constitui com frequência o ponto de fuga que ocupa uma parcela - obviamente minoritária - dos negros que são excluídos ou se auto-excluem do mercado de trabalho desqualificado. É neste ponto que a construção de uma nova etnicidade se coloca.

Como afirma Sansone (1999) há uma internacional "classificação do corpo negro" como portador de uma disposição congênita para a música, a dança, os esportes e etc. O negro é tomado como sensível, fisicamente desenvolto, lúdico e próximo da natureza. Esta caracterização essencialista, se por um lado, aprisiona o negro numa posição anti-moderna (porque vinculado à natureza e não à racionalidade, porque natural e não tecnológico), por outro é, em contextos nacionais diferentes, tomada pelos próprios negros e utilizada para se apoderar de nichos do mercado de trabalho.

Embora haja uma forte tendência das "culturas negras" locais a tomarem o modelo de etnicidade negra norte-americana como padrão universal, devemos reparar que aqui, as expressões afro-brasileiras, são totalmente permeáveis aos brancos (seja na religião, na música ou na moda).

Sansone (1999), apoiado em Gilroy (1993) afirma que a "cultura negra" brasileira apesar de suas especificidades é formada também pelos símbolos negros que circulam pelo "Black Atlantic", com forte influência da Jamaíca (o reggae) e dos Estados Unidos (funk e rap).

Mas qual a relação entre cultura negra e identidade étnica negra ? Com base em suas pesquisas na Região Metropolitana de Salvador, Sansone (1999) afirma que as opções de auto-exclusão dos negros do mercado de trabalho não estão relacionadas à atitudes étnicas ou fundadas na etnicidade, mas à construção de caminhos individuais de ascensão social, por fora dos lugares "reservados" aos pobres."

Igualmente não há no Brasil um "voto negro" nos pleitos eleitorais, ou seja; há mais "cultura negra" que "identidade negra". Aqui devemos propor uma diferenciação entre ambos, através da noção básica de que a identidade étnica:

“...pode ser entendida como aquela dimensão da identidade social relacionada ao fato de pertencer a um grupo étnico. Além de sua dimensão social - a coesão étnica, a organização social de um grupo étnico - ela contém uma dimensão de natureza ideológica."

(Sansone, 1992:144)

Já a "cultura negra" não se refere diretamente a formas de coesão e luta política (embora possa ser usada para tal), mas sim à elementos que remetem á etnia (que podemos vagamente definir como o sentimento de uma origem histórica comum) e que podem ser utilizados de forma híbrida com outros valores, e de forma individual ou coletiva. 
Assim, no Brasil é latente um caráter "negociado" e pouco fixo das identidades étnicas; que se diferencia substancialmente de uma etnicidade negra "imaginada"" (com uma representação da passado), que consiste numa reserva internacional de símbolos, tomada pelas várias formas que pode assumir a "cultura negra".

A etnicidade, portanto, pode significar parte ou mesmo elemento estruturador de estratégias de sobrevivência em face da exclusão e auto-exclusão do mercado de trabalho.

As formas de manipulação do étnico fazem parte de mecanismos que são produzidos em relação ao cotidiano local (assim há uma diferenciação entre a etnicidade negra na Bahia e no Rio de Janeiro, e entre o Brasil e a Holanda, por exemplo), entendido em sentido amplo (cultural, econômico e social). Ou seja, os negros podem optar por construções étnicas fechadas ou abertas aos brancos; pelo maior ou menor uso do corpo; por preencher um segmento do mercado de lazer; ou optar pelo status religioso; enfim o que resulta disso tudo é que não há uma forma de sobrevivência que seja por essência particular aos negros."

Sansone (1999) nos fala assim, de uma juventude negra com expectativas de consumo e bem-estar muito acima do lugar sócioeconomico que em grande maioria ocupam" e dos trabalhos difíceis e mal remunerados que encontram. Neste quadro de difícil acesso às perspectivas de consumo colocadas pela metrópole moderna, a inclusão do racismo e a auto-valorização através da leitura positiva do estereótipo essencialista aparece como interessante estratégia de aquisição de status e renda.

O racismo ocidental essencializa o corpo negro do outro lado da modernidade (mais para tambor do que para computador), como seres eternamente vinculados à natureza do ancestral território, uma África de matas, leões e girafas ${ }^{12}$; seres que são ótimos para o esporte $^{13}$, para a musica e para a dança; corpos carregados de sensualidade, aptos para o uso sexual, mas também corpos com inata força física e habilidade manual.

Apesar da enorme importância da crítica anti-essencialista de Bhabha (1998), não podemos escapar da observação acerca do devir concreto dos negros no Brasil (e mesmo em outros países do mundo), que nos indica a possibilidade de uso positivo do essencialismo; acrescentando ao enquadramento étnico, os símbolos coletados internacionalmente, no devir diaspórico das culturas negras

Para alguns segmentos dos negros, aproveitar este conjunto de estereótipos essencialistas e tomá-los como "qualidades da negritude" consiste numa possibilidade individual de ganho econô- 
mico que, no mínimo, pode substituir o emprego como entregador de refrigerantes ou faxineira.

As indicações de Sansone, podem ser comprovadas com facilidade e abundância qualitativa se nos detivermos nos artigos da seção "Black", publicados no Jornal Folha de São Paulo, entre outubro de 1994 è dezembro de 1998.

Neste período selecionado, a seção "Black", sempre redigida por negros, tinha como objetivo divulgar trabalhos (em geral) de negros ou voltados para os negros, com expressão local ou nacional; divulgar um roteiro cultural vinculado com este público e simpatizantes; além de discutir temas de interesse dos negros e dar dicas de consumo para estes. Uma coluna prioritariamente voltada para jovens negros, mas também passível de interessar jovens em geral.

No período que estudamos, foram publicados 178 artigos, sempre aos domingos. Elaboramos uma divisão dos artigos por assunto, para verificarmos o percentual de aparecimento destes. É o que temos no quadro abaixo.

\begin{tabular}{|c|c|}
\hline \multirow{2}{*}{\multicolumn{2}{|c|}{$\begin{array}{c}\text { Quadro } 1 \text { - Assuntos da coluna "Black" (Jornal Folha de São Paulo) } \\
\text { entre outubro de } 1994 \text { e dezembro de } 1998 \\
\text { (por percentual de aparecimento) }\end{array}$}} \\
\hline ASSUNTOS & \\
\hline Musica, boates de black music e carnaval & 35,39 \\
\hline Moda, modelos, beleza e cosmética & 16,85 \\
\hline Dança, teatro, cinema, TV e vídeo & 10,67 \\
\hline Racismo, discriminação e movimento negro & 7,86 \\
\hline Artes plásticas e fotografia & 5,61 \\
\hline Saúde & 4,49 \\
\hline Consumo negro, propaganda, e feiras & 4,49 \\
\hline Outros & 4,49 \\
\hline Livros e revistas & 2,80 \\
\hline Gastronomia e bares & 2,24 \\
\hline Centros culturais e clubes & 1,68 \\
\hline Educação & 1,12 \\
\hline Mulher negra & 1,12 \\
\hline Religião & 0,56 \\
\hline Internet & 0,56 \\
\hline Fonte: Jornal Folha de São Paulo, anos de 1994 à 1998. & \\
\hline
\end{tabular}

Como podemos visualizar a coluna "Black" é voltada de forma expressiva para atividades artísticas feitas por negros. Nos artigos 
que agrupamos em "musica, boates de black music e carnaval", o maior peso é da "musica", que aparece em 48 artigos (sobre casas de black music temos 10 artigos e sobre carnaval 5).

Nestes 48 artigos sobre musica negra alguns padrões podem ser detectados. De início vários artigos fazem referência à variável "periferia". Ou seja, explicitam uma associação entre os negros ou a "cultura negra" e áreas periféricas que são problemáticas para os adolescentes.

É o caso da matéria "Opera rap põe o pé na estrada" (FSP, 22/01/ 95), na qual o elenco da referida ópera, composto por adolescente entre 10 e 15 anos, é anunciado como saído das ruas da periferia de Sorocaba; mais do que isto estes adolescentes estão "mostrando do que são capazes para além do submundo."

A matéria "Rock e rap vão dividir a praça" (FSP, 23/06/95), onde são anunciadas apresentações com "novas bandas da periferia" nas praças públicas da cidade de São Paulo. O "evento" é organizado pela Câmara de vereadores e prefeitura da cidade e pretende alcançar objetivos educativos através da distribuição de panfletos sobre drogas e AIDS. NA última linha a conclusão do autor: "Grupos de periferia lutam para passar uma imagem decente e mostrar que rock e rap não são sinônimos de violência".

Em 27/07/97 é publicada a matéria "14 anos nas ruas" que se refere ao avanço do Hip Hop ${ }^{14}$ da clandestinidade para a aceitação social. A matéria ao final, transcreve uma fala de um participante de uma ONG vinculada a luta pelos direitos dos negros, que referindose ao Hip Hop afirma: "É o movimento mais politizado e pacifista da juventude negra, uma alternativa cultural das comunidades carentes." Esta fala carrega dois traços interessantes; a tentativa de caracterizar uma forma de diversão de jovens negros como expressão política ou como forma de identificação étnica e, a direta associação entre negros e pobreza ou carência.

A matéria "Entre nesta festa" (FSP, 10/08/97) se refere ao espetáculo musical "Palco, Academia e Periferia". O espetáculo faz uma mistura "artística, alegre e positiva que fala também da violência, das particularidades, do movimento e dos ritmos negros", e é feito por "comunidades carentes". Um dos idealizadores, o percussionista negro Naná Vasconcelos afirma ainda: "É um espetáculo forte porque dá oportunidade para as comunidades carentes emitirem suas opiniões e se sentirem úteis". Mais uma vez a confusão entre negros e comunidades carentes é total.

"Hip Hop para pensar" de 14/09/97 divulga o "1. Encontro de Cultura de Rua do ABC", na cidade de Santo André, onde se apresentarão grupos de rap, DJ's, grafiteiros e dançarinos de break. O 
evento é organizado pela prefeitura local e por uma ONG (Associação Cultural Negro e Atividade). A coluna black afirma que o encontro é um importante momento para "mostrar os aspectos positivos da música, arte e dança black - muitas vezes consideradas expressões marginais"; e também para a "discussão dos problemas que rondam a periferia - em especial a comunidade negra e pobre." Mais uma vez o Hip Hop é lido por um ativista dos direitos dos negros como movimento de conotação política e coletiva: "É a forma que a periferia encontrou para se sentir viva, reclamar, protestar e resgatar suas raízes." Afirmação de todo vazia, se perguntarmos de qual "raízes" esta se falando?

É um dado estatístico que as populações de áreas periféricas são em maioria negras. Podemos verificar isto tomando alguns indicadores de população por raça segundo o IBGE.

\begin{tabular}{|c|c|c|c|c|c|c|}
\hline \multicolumn{7}{|c|}{$\begin{array}{c}\text { Quadro } 2 \text { - População total por raça de unidades territoriais } \\
\text { selecionadas em } 1991\end{array}$} \\
\hline branca & preta & amarela & parda & indigena & $s / d e c l$. & total \\
\hline 75.704 .922 & 7.335 .130 & 630.658 & 62.316 .085 & 294.148 & 534.872 & 146.815 .815 \\
\hline $\begin{array}{ll}\text { Est. do } & \\
\text { RJ } & 7.022 .300 \\
\end{array}$ & & & 4.373 .045 & & 82.781 & 12.807 .197 \\
\hline $\begin{array}{l}\text { Cidade } \\
\text { do Rio } \quad 5.240 .012\end{array}$ & 965.689 & 13.228 & 3.520 .591 & 5.191 & 67.434 & 9.814 .574 \\
\hline D.Caxias 274.613 & 82.917 & 582 & 305.881 & 681 & 3.147 & 667.821 \\
\hline 52.605 & 11.972 & 501 & 47.743 & 58 & 178 & 113.057 \\
\hline 75.879 & 28.944 & 307 & 85.683 & 63 & 858 & 191.734 \\
\hline Nilopolis & 17.457 & 89 & 68.682 & 41 & 450 & 158.092 \\
\hline N.Iguaçu 531.789 & 170.966 & 545 & 584.413 & 871 & 9.120 & 1.297 .704 \\
\hline S.J.Meriti 171.267 & 60.940 & 343 & 190.277 & 245 & 2.700 & 425.772 \\
\hline $\begin{array}{l}\text { Baixada } \\
\text { Flumin. } 1.177 .526\end{array}$ & 373.196 & 2.367 & 1.282 .679 & 1.959 & 16.453 & 2.854 .180 \\
\hline
\end{tabular}

No conjunto da população brasileira em 1990, os negros constituem $47,44 \%$. Na Região Sudeste esta proporção é de $36,09 \%$. No Estado do Rio de Janeiro atinge 44,32\%. Na Região Metropolitana do Rio de Janeiro temos $45,71 \%$ de negros no total da população. No que tange à Baixada Fluminense ${ }^{15}$, a presença de negros totaliza 58,01\%.

Este peso acentuado da população negra nesta região não consiste em uma desproporção estatística, na medida em que, nos seis municípios a população negra é superior numericamente à população branca. ${ }^{16}$ Com características especificamente periféricas, grande incidência de pobreza e violência urbana e composta por várias "cidades-dormitório", umas mais, outras menos industrializadas; a Baixada Fluminense cons- 
titui um exemplo da desigualdade racial em meio a um padrão de pobreza e espacialidade típicos das regiões metropolitanas.

Além das vários aspectos que impactam a qualidade de vida da população desta região, tais como grande distância dos mercados de trabalho mais dinâmicos da região, precariedade da estrutura de transportes, grande concentração de domicílios inadequados e com infraestrutura inexistente; a violência - típico efeito do abandono do Estado - consiste num elemento que se impõem com poder avassalador no cotidiano destas populações. Segundo dados do SUS, referentes ao ano de 1997, estes municípios que compõem a Baixada Fluminense, se encontram entre os mais violentos do Estado do Rio de Janeiro no que tange à taxa de homicídios por 100.000 habitantes; numa escala que vai da taxa de 76,6 em Duque de Caxias a Magé com 59,1. Vale ressaltar que mesmo neste último município, a taxa de homicídios em 1997 foi maior que as dos tristemente famosos municípios violentos de São Paulo e Rio de Janeiro.

Portanto se é inegável como dado de realidade a presença de negros em maior quantidade que os brancos nas áreas de periferia, o que apontamos é a associação que aparece na coluna "black" entre as manifestações culturais negras e estas áreas, como se a "cultura negra" fosse a representação clara destes locais, ou a única manifestação artística saída deles. A voz que fala da periferia para o centro seria então a voz negra. A voz dos carentes seria também a voz negra.

É interessante também observar que das 48 matérias sobre musica negra, 10 se referem à musica internacional; seja no sentido de World Music, seja no sentido de black music (definida na coluna "Black" de 29/11/98 como: "o gênero musical derivado da diáspora negra africana, como o blues, o samba, o soul, o funk e até o moderno drum \& bass"). São matérias sobre grupos e cantores individuais, bem como sobre os CD's lançados. É igualmente interessante que haja somente 01 matéria sobre "pagode", que é um ritmo estritamente brasileiro, também muito associado aos negros.

Acreditamos que esta configuração de interesses, que se manifesta na coluna "Black", está diretamente ligada à constatação que aparece em Gilroy (1995) e Sansone (1995 e 1999) acerca da direta vinculação entre a cultura negra e a modernidade urbana ocidental. Cabe aqui, um exemplo oriundo de minhas atividades de pesquisa e extensão universitária como docente da Universidade Federal Fluminense. Entre 1995 e 1998 trabalhei com comunidades remanescentes de quilombos na região dos rios Trombetas e Erepecuru no município de Oriximiná-PA. Ao iniciar o trabalho esperava encontrar agrupamentos humanos com grande numero de elementos 
culturais africanos preservados, como fósseis conservados em meio ao isolamento amazônico. $\mathrm{Na}$ verdade não encontramos nenhuma "tradição" cultura conservada in vitro após tantos anos de vida na floresta. O que vimos foram comunidades totalmente cristãs no que tange às práticas religiosas (principalmente católicas, mas com presença já acentuada de seitas pentecostais), que na festa anual do padroeiro da comunidade (sempre um "santo" da igreja católica), ouvem e dançam ritmos regionais como o brega e o forró. Sobrevivem através de formas produtivas absolutamente idênticas aos dos chamados "ribeirinhos" da Amazônia brasileira (pesca, caça e cultivo da mandioca principalmente). Sem eletricidade, não assistem televisão e igualmente não têm acesso sistemático à cultura urbana moderna, estão portanto muito longe da noção de negritude que a coluna "Black" veicula.

Esta vinculação entre a cultura negra e a modernidade urbana ocidental se aprofunda com a globalização que, ao facilitar a velocidade das trocas internacionais de som e imagem, disponibiliza para os "produtores" da cultura negra uma miríade de possibilidades de recomposições, misturas, releituras, traduções, adaptações e mesmo plágios culturais. A "cultura negra" jovem, "de ponta", está muito mais associada ao trânsito internacional de ritmos e imagens étnicas (com as mais variadas origens: a América do Norte, a África ou a Jamaíca) do que à retomada de tradições brasileiras como o pagode enquanto releitura do samba. ${ }^{17}$

Duas matérias sobre musica se referem à corais. Aqui a retomada étnica é clara. Em "mais voz aos sons do globo" (FSP, 14/05/95) a coluna "Black" dá visibilidade ao "coral étnico Mawaka" formado só por mulheres negras, e lembra que o nome significa "cantoras em dialeto africano". Entre o repertório do coral está uma cantiga de ninar africana "Àllundé, Alluya". As musicas utilizam como instrumento musical de percussão o kalimba, que seria também "usado em países da África." Nesta matéria é interessante verificar com a tentativa de essencializar uma atividade musical toma como referência a "África" como realidade única, como se o continente somente tivesse um dialeto, o "dialeto africano".

A segunda matéria (de 10/11/96) é sobre os 26 anos da Comunidade Coral Luther King. Este, embora mais eclético que o coral citado no parágrafo acima também não deixa de se referir à África. Canta musicas que vão do "barroco brasileiro e spirituals norte-americanos às canções de tribos da África. O repertório inclui a canção 'N'Kosi Si Le Le Africa' - hino oficial da Africa do Sul. O fato de "não falar o zulu e outros dialetos africanos não é obstáculo." 
A associação entre musica negra / músicos negros e África aparece em mais 04 artigos. Dentre estes, em 29/06/97, a matéria "Sons além da imaginação" fala de um etnomusicólogo negro que conseguiu reunir instrumentos musicais de origem africana e "... resgatou instrumentos utilizados em manifestações religiosas, datas comemorativas de comunidades negras e mestiças." No fim da matéria, a opinião da coluna "Black" conclui pela "importância de preservar instrumentos musicais que mantêm viva uma etnia".

A idéia da "África como banco de símbolos" (Sansone, 1995 e 1999) é bastante apropriada para compreendermos estas referências constantes ao continente originário.

$O$ segundo maior percentual de assuntos que aparece na coluna "Black" é "Moda, modelos, beleza e cosmética". Especificamente sobre moda a referência à África é também recorrente.

Em "Cultura zulu faz moda paulistana" (FSP 26/02/95), a coluna "Black" apresenta um estilista (não identificado como negro ou branco) que viajou pela África, mais especificamente "por Soweto e Johannesburgo, na África de Mandela, Sommer fez amigos, foi às tribos, participou dos rituais da tribo zulu. Constatou que é preciso passar um pouquinho disso para o Brasil, aplicando aqui cores e traços de um povo salvo por seu orgulho". A matéria termina com o sempre recorrente "Black is beautiful!"

A afirmação "O cstilo africano toma força e já sobrevive como conceito por aqui.", está na primeira linha da matéria sobre uma estilista negra: "Além do pano na cabeça" (FSP, 05/11/95). A estilista traz em sua bagagem profissional o fato de ter vivido seis anos na África; a informação de em qual lugar da África parece não ser importante. A confecção tem o sugestivo nome de Awa Adesin ("respeito às raízes". em "dialeto africano" segundo a coluna "Black").

Em "Toque afro" (FSP, 04/05/97), a coluna fala de uma artista plástica (não identificada como negra ou branca) que antes da África ter voltado à influenciar a moda, "já havia encontrado um meio de trabalhar e sobreviver com materiais que embelezam o corpo e mantêm vivos a arte e o espírito criativo daquele continente." Para finalizar a palavra da artista: "É uma arte de raízes que traz embutido o misticismo e alegria festiva da cultura negra"

Em "Moda afro em cena" (FSP, 19/06/98) a coluna "Black" divulga a criação da griffe Afonjá, iniciativa de uma "rede black de salões de belcza do eixo Rio-São Paulo" de mesmo nome. A griffe tem como publico-alvo "negros e brancos que valorizem a cultura afro-brasileira". e produz roupas que se adequam c realçam a cor e a estrutura física do 
negro. Aqui, menos do que uma ida ao "banco de símbolos" africanos, chama nossa atenção um não muito discreto essencialismo físico.

Nas 26 matérias que classificamos em "Dança, teatro, cinema, TV e vídeo", a dança é predominante. Vejamos alguns exemplos interessantes.

Em "O valor da arte afro-brasileira" (FSP, 11/02/96), aparece a "Cia. Étnica de Dança e Teatro Experimental", criada e dirigida por uma negra com formação em direção de teatro e dança pela Universidade de Washington. A companhia é voltada exclusivamente para atores negros. Segundo a coluna "Black", o objetivo é "incentivar o intercâmbio global, valorizar o artista afro-brasileiro, formar profissionais das artes cênicas e conscientizar e integrar a população afro-brasileira".

O ritmo "afro-jazz" é anunciado na matéria "Do samba para o afro-jazz" (FSP, 31/03/96). O professor (não identificado como negro ou branco) aprendeu dança moderna e na Bahia aprendeu a "a dança dos Orixás."

"Se você quer malhar, experimente a dança Afro!" É a alternativa anunciada na matéria "Mexa o corpo com ginga" (FSP, 30/06/ 96). O professor (também não identificado como negro ou branco) aprendeu a dança afro na "primeira companhia de dança negra contemporânea de São Paulo." Estas aulas de dança afro, porém se estendem pelo estudo da "história da dança afro primitiva, tradicional e contemporânea."

Em "Dança e história" (FSP, 29/03/98), a coluna "Black" se dedica ao "curso de danças e cantos afro-brasileiros do Sudeste". Para a preparação deste, o professor (não identificado como negro ou branco), "percorreu de terreiros de candomblé a escolas de samba e festas populares onde a presença do negro é marcante. E conseguiu resgatar algumas raízes."

As dificuldades dos modelos negros também aparecem em várias matérias. Nestas a tônica gira sempre em torno da pouca participação de modelos negros nos desfiles de moda, ou do baixo numero de modelos negros nas agências importantes.

Na matéria "Gata preta em zinco 'gelado'" (FSP 17/10/94), é contada a história de uma modelo negra, carioca, com 21 anos que somente conseguiu espaço no Brasil depois de desfilar na Europa e no Japão para grifes importantes do mundo fashion. A matéria, num tom otimista diz: "ainda vamos batizar uma agência de 'Black is Beautifull Top Models' ". Termina informando que a agência Elite tem três mulheres negras e dois homens negros; a Ford tem quatro mulheres negras e dois homens negros e a L'Equipe tem duas muTheres negras e dois homens negros, enquanto "no país, $70 \%$ da população é de origem negra." 18 
"Realçando a beleza negra" é o título da matéria (FSP, 03/11/96) sobre a criação de uma agência de books somente para modelos negros, onde os fotógrafos são também todos negros.

Em "Garimpando talentos" (FSP, 30/03/97), a coluna "Black" informa o nascimento de uma agência de modelos para "negros e pobres". Funcionando na periferia da cidade de São Paulo, já há um cadastro de 350 modelos para desfiles. Como afirma a empresária e modelo negra, de 22 anos: "Faltam oportunidades e condições financeiras e, por isso, a auto-estima geralmente está em baixa". Vemos aqui mais uma vez a associação direta entre negros e habitação em periferias urbanas.

"Black is beautiful". Título nada inovador para uma matéria sobre modelos negras (FSP. 22/02/98). Além de lamentar o não crescimento do numero de negros nos desfiles (apesar da ser esta uma tendência internacional), são citados modelos que fizeram sucesso no encerramento do evento Morumbi Fashion Brasil. Uma destas, com 28 anos e participando de seu primeiro desfile de peso em 16 anos de carreira diz: "Aqui, a modelo negra não é aproveitada muito mais pela falta de visão do mercado do que por preconceito. Tem muita gente boa que não está sendo vista. Será que eles acham que o negro não vende nem consome?"

Outra agência de modelos com clientela tipicamente negra é o alvo da matéria "Made in Brazil" (FSP, 15/03/98). Trata-se da agência New Company que possui 1.200 modelos cadastrados, "a maioria negros e mestiços." A ex-modelo e produtora responsável pela agência (não identificada como negra ou branca) informa ter também "uma filial ... em Weimar, na Alemanha, para administrar a carreira e cuidar da imagem das modelos negras na Europa."

Em "Consciência por baixo dos panos" (FSP, 30/08/98), a coluna "Black" comenta a presença crescente de modelos negros nas passarelas intemacionais, desfilando para as mais caras e renomadas grifes e critica o fato de no Brasil isto não ocorrer: "No mercado internacional, os negros aparecem agora vendendo produtos luxuosos e disputados. A modelo negra sudanesa Alex Wek, por exemplo, é top da marca Joop! Mas isso ainda não se aplica por aqui. Uma pena, já que empresários, e até publicitários, continuam achando que relacionar negros a alguns produtos é perder a parte branca do mercado consumidor."

Estas matérias tocam num aspecto importante das relações raciais no Brasil. Apesar da leitura sensual que é feita da mulher negra, o modelo de beleza nacional ainda é a mulher branca e de preferência loira (ainda que a cor clara dos cabelos seja, sabidamente, artificial).

Nesta mesma direção encontramos interessantes matérias sobre feiras específicas para consumidores negros ou para venda de "pro- 
dutos negros".

Assim, "Um mercado negro" (FSP, 21/04/96), anuncia a $1^{\circ}$ Fashion Black, um "mercado aberto voltado para a cultura negra". Para os organizadores, o evento pretende "a valorização e divulgação da cultura negra. Sentíamos falta de representantes negros nos outros mercados da cidade."

A matéria "QG da vaidade negra" (FSP, 07/12/97), fala da "Etnic 97", uma feira de moda, beleza e fitness para os consumidores negros, com mais de 150 expositores. Trata-se de um evento de grande porte no qual, em paralelo à Feira acontecerão, o $1^{\circ}$ Salão Internacional de Cabeleireiros Afro Étnicos, o $1^{\circ}$ Salão Internacional de Cosmetologia Afro Étnica e o $10^{\circ}$ Congresso de Cosmetologia Capilar.

"Dia de passear na feira" (FSP , 05/07/98) é uma matéria que anuncia a edição 98 da Fashion Black. Para a organizadora do evento, de ano a ano melhora a participação do público e dos consumidores negros: "A auto-estima negra agora está em alta". A partir disto, a organizadora acredita estar ajudando a formar "um mercado negro". No entanto, são aceitos expositores de qualquer raça, "desde que respeitem essa característica".

No que tange à "beleza" e "cosmética" encontramos 10 matérias; vejamos as mais interessantes.

Em "Beleza pede um toque de sutileza" (FSP, 12/03/95) a coluna "Black" dá inúmeras "dicas" de maquiagem para mulheres negras, e termina com a nada inovadora formula que tantas vezes aparece nos 178 artigos usados para a composição deste nosso trabalho: "Black is beautiful!"

"Beleza negra em alta" (FSP, 12/05/96), convida o publico para o "Encontro de Beleza Negra" onde serão apresentadas "novidades sobre cosméticos para negros".

Em "Vai uma trança aí?" (FSP, 03/08/97), a coluna "Black" divulga o trabalho de uma cabeleireira negra de 21 anos, especializada em tranças de dreadlocks. A cabeleireira que modela cabelos lisos ou crespos fala: "Além dos negros, os brancos estão fazendo tranças e dreads. É maravilhoso. Tenho orgulho de senti-los vivendo um momento black". Um dos requisitos que a coluna aponta ser necessário para fazer um penteado deste tipo remete, diretamente, ao contexto da modernidade globalizada: "mente aberta para as novidades."

A matéria "Crescimento maquiado" (FSP, 04/10/98), reclama da pouca variedade de produtos de cosmética para negros. Segundo a matéria, ao contrário do que ocorre nos Estados Unidos, aqui "o empresariado demonstra grande receio em assumir um mercado claramente segmentado", e os profissionais de publicidade preferem a 
imagem das mulatas que contemplam necessidades das negras e das brancas sem cabelos lisos.

No campo da fotografia, encontramos algumas matérias que apontam para o tema deste trabalho.

Em "Retratando as raizes" (FSP. 13/04/97), a coluna "Black" anuncia a inauguração de uma exposição de fotografias de dois nigerianos. As fotos seriam "um dicionário ímpar da cultura negra". Um dos fotógrafos, Rotimi Fani-Kayode que morreu em 1989, "registra um universo sensual, místico, com símbolos africanos." Já o outro, Seydou Kheita, retrata uma realidade amena e fundamental para o entendimento das raízes negras. São 45 fotos em P\&B que lançam um olhar sem artifícios para homens e mulheres de sua aldeia."

"Você conhece a África?" (FSP, 01/11/98) anuncia o inicio da exposição "Antologia da Fotografia Africana". As fotos, seriam "registros que contam hábitos, costumes, passagens conflituosas ..., mostram o cotidiano e também enfocam a riqueza e a nobreza africanas." A exposição tem ainda fotografias de autoria de brasileiros, franceses, cubanos, americanos e canadenses "que registraram a diáspora negra pelo mundo nas últimas décadas."

No campo das artes plásticas, duas matérias se destacam.

A primeira é "Questão de pele" (FSP, 17/05/98), onde é anunciada a primeira exposição de um fotógrafo brasileiro (não identificado como negro ou branco) que "estuda as formas e a textura do corpo negro." O fotógrafo diz que pretende "estar dando sua contribuição para que a estética negra seja melhor valorizada e o preconceito seja visto com outros olhos... Negro é arte!"

A segunda é "Tirando a máscara" (FSP, 24/05/98), que também anuncia uma exposição de variadas peças (máscaras, lanças e instrumentos agrários"), comprados em tribos africanals do Gabão, Costa do Marfim, Mali e Congo. Segundo a coluna "Black", as peças "preservam a riqueza e o conteúdo simbolista místico. cultural, ritualístico e artístico da população".

Os artigos sobre saúde estão principalmente em dois blocos: saúde da pele e saúde psicológica. Há no entanto uma matéria que se refere à "doenças étnicas". Com o título "Negro e saúde" (FSP, 20/ 07/97), a coluna "Black" pretende divulgar o trabalho da ONG "Fala Preta", que mantém um serviço de orientação psicológica c tratamento de saúde para negros. A matéria afirma que saber quais são as "debilidades e propensões a doenças da sua etnia pode se tornar uma questão de vida ou morte"; c ainda que há problemas que ocorrem com frequência entre a população negra porque são resultado de "agravantes sociais (miséria, analfabetismo) aos quais a popu- 
lação negra - por viver majoritariamente numa faixa de pobrezaestá mais exposta. Aids e uso de drogas se enquadram nesse item."

"À flor da pele" (FSP, 24/08/97) é a matéria que afirma que "a genética explica as diferenças. Por fora, certos problemas se manifestam à flor da pele... negra." A partir daí são dadas informações sobre como o negro pode, através do conhecimento "das particularidades da sua etnia", prevenir e resolver problemas de pele que thes são comuns.

Já em "Ler para aprender" (FSP, 07/06/98) a coluna "Black" divulga a chegada ao Brasil (via importação e distribuição feita pelo laboratório Bristol-Myers Squibb Brasil) do "Dermatological Atlas' of Black Skin", escrito, pelos americanos Joyce Connoly e Joseph Birowski e recomendado para uso médico. O livro contém "fotos e textos sobre doenças que acometem os negros."

Dentre as 08 matérias sobre saúde do negro, 03 são referéntes à saúde psicológica. Todos se referem à serviços de psicologia privados, voltados para negros.

Uma destas instituições, é a Amma (FSP - 23/07/97; segundo a coluna "Black", este é o nome, "em africano", da entidade "responsável pelo sopro da criação, o início de tudo"), que aparece na matéria "Psicologia do Anti-racismo". As psicólogas negras que atuam nesta instituição afirmam: "o preconceito, o racismo e a opressão afetam a auto-estima, fragilizam o ser, dificultam a sociabilização e causam doenças somáticas como a hipertensão."

"Em busca do ego perdido" (FSP, 07/09/97), também faz propaganda de uma clínica de psicologia para negros. A coluna "Black" diz que a psicóloga responsável pelo trabalho já descobriu que problemas como violência, alcoolismo, uso de drogas, e outros podem ser decorrentes de "fatores como a falta de auto-estima e o conhecimento das suas raízes." A psicóloga responsável (não identificada como negra ou branca) diz ainda que as crianças negras são passíveis de problemas porque: "têm um bombardeio da cultura branca, mas são completamente diferentes. No caso da família negra, por exemplo, é comum haver uma inversão de papéis. $\mathrm{O}$ homem se desvaloriza, a mulher trabalha fora e ainda assume o comando da casa e da família. Os filhos crescem sem nenhuma orientação sobre sua etnia."

$\mathrm{Na}$ matéria "Férias produtivas" (FSP, 11/10/98), a coluna "Black" afirma que a ascensão social do negro é acompanhada de um isolamento de "suas raízes, de seu meio e de sua identidade culturais." Esta constatação levou duas psicólogas (não identificadas como negras ou brancas) a montar projetos voltados para crianças e adolescentes negros. Segundo a psicóloga responsável, há um conjunto de dados históricos que contribuem "para que o negro tenha 
um espírito gregário acentuado, com o forte contato com a natureza e a escravidão - que fez os negros desenvolverem um sentido de união muito maior no Brasil."

O essencialismo presente nestas matérias sobre opções de tratamento psicológico para negros é inequivocamente visível.

Duas revistas são divulgadas pela coluna "Black". Uma delas na matéria "Negritude em revista" (FSP, 08/09/96). Trata-se aqui da " 'Raça Brasil' - uma revista mensal, da editora Símbolo, sobre a cultura black." O objetivo desta, nas palavras de um dos editores, é produzir uma publicidade dirigida para os negros, com produtos específicos, ao lado de reportagens informativas e variadas sobre "comportamento, moda, turismo, música, culinária e beleza."

Em "Quem te viu, quem te vê" (FSP, 25/05/97), encontramos uma matéria que fala do avanço dos negros na mídia internacional e reflete a ausência destes da mídia nacional. No corpo da matéria encontramos a divulgação da revista "Agito Geral" (editora Dipreto), que empreende uma campanha contra as marcas comerciais que não usam negros em suas propagandas. Nesta revista, há em todos os números o anúncio: "Cruze os braços contra a discriminação na publicidade. Não use nada na qual você não veja seu rosto". O editor justifica a campanha afirmando: "É uma questão de postura. Estamos incluídos em um padrão que não é o nosso. Agressivo é fechar os olhos e perpetuar o que sempre aconteceu. " "

Há somente duas matérias sobre educação. A primeira é "Educação para homens livres" (FSP, 06/07/97) que divulga o trabalho de um curso de línguas (inglês, francês e espanhol), criada por dois negros, que pretendem fundar uma "universidade negra". Por enquanto, os cursos de língua tem preço muito abaixo do mercado e, os alunos recebem também ensinamentos de história e geografia através de "professores vindos de Cuba, Burkina Faso e São Tomé."

Na segunda "Antes da universidade" (FSP, 26/04/98), a coluna "Black" discute a irrisória presença dos negros no ensino superior, para divulgar um curso pré-vestibular para "negros e carentes" criado por uma ONG em parceria com "profissionais da USP".

Sempre próximo ao "dia das crianças" (12/10), duas matérias interessantes se dedicam a brinquedos infantis. Em "O charme da Barbie negra" (FSP, 08/10/95), a coluna "Black" afirma já estar à venda no mercado de São Paulo a versão black da boneca Barbie. A importadora de brinquedos que faz a distribuição trouxe dos Estados Unidos dois modelos, "a queniana, que vem vestida a caráter, $\mathrm{c}$ a mágica, uma Barbie bebê de fibra maleável que fecha os olhos quando se molha seu rosto." Também estão sendo vendidos o que a 
matéria chama de "bonecos étnicos "made in Brazil" ".

"Auto-estima em forma de brinquedo" (FSP, 12/10/97) fala de bonecas negras que podem dar às crianças "um pouco mais de referências da cultura black." Segundo a criadora destas bonecas (não identificada como negra ou branca): "É importante para a criança negra se identificar com a boneca. Ela passa a melhorar a auto-estima".

Uma interessante matéria é "www.negro?" (FSP, 25/10/98), onde aparece a discussão do racismo na Internet. A matéria faz referência à texto publicado na revista norte-americana "Business Week", que afirma as grandes possibilidades de negócios que a internet dá a negros que por não serem identificados naquele meio conseguem vender melhor seus produtos, fugindo da discriminação racial. Para além deste aspecto positivo, a matéria afirma que no Brasil algumas pessoas se escondem na rede, e só revelam a negritude em último caso. "Começar a assumir a sua raça navegando é um espaço importante para o fortalecimento de sua cidadania." A coluna propõem que os leitores façam um teste: "...da próxima vez em que se conectar na Internet, assuma a sua negritude ou finja ser negro para saber como anda essa questão racial no cyberespaço".

Das 14 matérias que agripamos no ítem "Racismo, discriminação e movimento negro" (que representa $7,86 \%$ das 178 matérias), somente 3 se dedicam a denunciar ou discutir os problemas dos negros no mercado de trabalho.

Na matéria "Cartaz sindical antidiscriminação" (FSP, 28/05/95), a coluna "Black" informa que na próxima Convenção da Organização Internacional do Trabalho (OIT) uma comissão abordará o não cumprimento no Brasil da Convenção 111, de 1964, que versa sobre "racismo no mercado de trabalho". Afirma ainda que um "... grande problema brasileiro é que negros têm menores oportunidades de cargos e salários, mesmo exercendo funções idênticas às dos brancos."

"Bê-a-bá contra a discriminação" (FSP, 17/11/96) começa com a pergunta: "Você conhece a diferença entre racismo, discriminação e preconceito racial?" Isto para divulgar o lançamento da "cartilha Anti-Racista da Comissão Sindical Classista". O diretor do Sindicato dos Metroviários (que possui uma secretaria para monitorar a discriminação racial no trabalho) diz que: "Aqui o racismo é mais desumano porque é muito escamoteado",

Sob o título "O fim da "boa aparência" " (FSP, 18/01/98) a coluna "Black" informa a aprovação pela Câmara Municipal de São Paulo, da Lei ${ }^{\circ}$ lei ${ }^{\circ} 12.562$ do projeto 906/97, de autoria de um vereador (não identificado como negro ou branco) do Partido dos Trabalhadores. A Lei proíbe o uso da expressão " 'boa aparência' 
nos anúncios de recrutamento, concurso e seleção de pessoal em empresas públicas, privadas ou mistas, firmas individuais, entidades beneficentes, fundações e pessoas físicas." O uso do termo "boa aparência", segundo a matéria constituía uma "uma técnica racista" que impedia que profissionais negros qualificados (ou não) participassem de várias seleções para ocupação de vagas e postos de trabaIho. "Quando não era dita às claras, deixava subentendido, entre outras coisas, que "boa aparência' significava não ser negro."

Em resumo, no conjunto das 178 matérias da coluna "Black" que foram pesquisados para este trabalho, a grande maioria versava sobre aspectos de uma "cultura negra" que retomava constantemente 0 essencialismo e mesmo o afrocentrismo. ${ }^{10}$

Se dividirmos as matérias a partir de uma classificação algo aleatório entre os temas "lazer, beleza e cultura" (que flutuam no campo do lúdico na vida do negro) e "racismo, saúde e educação" (que flutuam no campo mais "sério" da vida dos negros); veremos que na primeira classificação estão $81,05 \%$ das matérias, enquanto $14,79 \%$ estão na segunda classificação (dos 4,49\% que classificamos inicialmente em "outros", a grande maioria aborda temas mais próximos da classificação "lúdica").

Para terminar, e com a pretensão de ilustrar parte das questões aqui discutidas, lanço mão de uma narrativa. Ontem, 18 de dezembro de 1999 fui a uma "Feira de Moda, Cultura e Lazer" consumo da classe média em diante, num clube da Barra da Tijuca onde - por acaso - resido. Na praça de alimentação do evento estava se apresentando um grupo de streetdance - o "New Black Dance". Todos os nove dançarinos eram negros. Do lado de fora do palco haviam mais quatro negros. Dois faxineiros que limpavam entre as mesas, um segurança que não estava prestando muita atenção ao show, e eu (contrariando as estatísticas como dizem os Racionais MC's), no meio de uma platéia de mais ou menos 50 brancos.

\section{Notas}

1 O estereótipo pressupõe a "fantasia" de uma "origem pura, não-diferenciada." (BHABHA, 1998: 125).

2 Estamos chamando de negros o que na classificação do IBGE aparecem como "pretos" e "pardos", posto que ambos os grupos apresentam nos estudos até agora realizados um quadro muito semelhante de vulnerabilidade sócio-econômica. Assim, seguindo as indicações de ANDREWS (1998), podemos afïrmar que, embora desde os tempos coloniais haja na sociedade brasileira uma 
classificação (no senso comum, nos discursos políticos e mesmo nos discursos acadêmicos) que separa "pretos" e "pardos" (ou mulatos), os censos demográficos desde 1940 e as PNAD's a partir da década de 1970, demonstram que os "pardos" apresentam níveis sócio-econômicos pouco melhores que os negros, porém muito mais próximos destes do que dos brancos. Neste sentido, as distinções históricas de longa duração no Brasil entre pretos e pardos, encobriram as semelhanças de posições sociais e econômicas e de dificuldades de ascensão social existentes entre os dois grupos. Vários autores que estudam a questão racial no Brasil fazem a mesma opção de agregação de "pretos" e "pardos" na categoria mais geral de "negros; por exemplo: OLIVEIRA (1985), LOVELL (1991), HASENBALG e SILVA (1988). Esta discussão no entanto, vai muito além destas poucas indicações aqui feitas. SANSONE (1995) acrescenta elementos importantes para pensarmos as várias classificações raciais existentes no Brasil, seus alcances e limites. Outra forma de definição possível consiste em tomar como negros aqueles que em um determinado contexto se vejam ou sejam vistos por outras pessoas como africanos ou descendentes destes (SANSONE, 1999).

3 A Pesquisa Nacional por Amostra de Domicílio é um levantamento realizado anualmente pela Fundação IBGE; que se baseia em uma amostra de probalidade, que atinge via de regra algo próximo de 120.000 domicílios (sempre excetuando as zonas rurais do Norte e do Centro-Oeste).

4 SANSONE (1992, 1993, 1995 e 1999)

5 A noção de Black Atlantic que aparece em GILROY (1995), pretende expressar as questões que circundam a lógica e o desenvolvimento cultural da "diáspora". Este autor se coloca no campo oposto da busca das raízes africanas que perdurariam nas culturas negras espalhadas pelo mundo. GILROY (1995) não se preocupa, portanto, com a descoberta de tradições negras autênticas entre os negros, mas sim com o mapeamento dos fluxos culturais que se interpenetram e se interconectam no Atlântico Negro.

6 Vale lembrar que Ernest Renan, autor de fins do século XIX, tem sido apropriado com relativa constância nas discussões contemporâneas sobre nação e nacionalismo. Seu texto clássico "What is a nation ?" foi republicado em uma coletânea organizada por BHABHA (1990).

7 BOURDIEU (1998), discutindo as escolas publicas de áreas peri- 
féricas na França, aborda esta questão e afirma que a escola possui a capacidade de criar expectativas para alunos pobres que não será capaz de realizar. Como afirma: "Os alunos ... de famílias pobres têm todas as probabilidades de conseguir, no final de uma longa escolaridade, muitas vezes paga com grande sacrifícios, nada mais do que um diploma muito desvalorizado". Assim, estes alunos pobres seriam os "excluidos com prazo marcado" (BOURDIEU, 1998: 483-484).

8 Conforme aparecem - como alegoria - nos painéis do metrô do Rio de janeiro, citados no início deste texto.

9 No sentido de ANDERSON (1989).

10 Devemos lembrar que a reestruturação produtiva do capitalismo que chega ao Brasil nos anos 1990 tem como uma de suas características a destruição dos postos de trabalho desqualificados ou mesmo manuais qualificados; ambos nichos do mercado de trabatho onde os negros sempre estiveram super-representados.

11 Apesar do inegável crescimento de uma classe média negra nas últimas duas décadas, este segmento é ainda ínfimo se comparado aos negros situados nas camadas mais pauperizadas dos trabaIhadores (ou definitavamente excluídos do trabalho) no Brasil.

12 Vale aqui lembrar uma das componentes do anedotário brasileiro sobre os negros, que em linhas gerais diz que estes tem o "pé largo" pelo fato de terem tantas vezes fugido de leões na África.

13 O cineasta negro norte-americano Spike Lee divulgou internacionalmente a expressão de duplo sentido. mas a priori referida ao basquete (esporte com esmagador predomínio negro nos Estados Unidos): "homens brancos não sabem enterrar."

14 O Hip Hop não é somente uma fórmula musical. Nascido nos Estados Unidos, contém em seu interior um ritmo específico que é o rap (rythm and poetry), formas de dança (principalmente o Break e o Streetdance) e um tipo alternativo de artes plásticas (o grafite - inscrições e desenhos feitos em paredes e muros de espaços públicos e mesmo de espaços privados como fachadas de casas e edifícios).

15 Mais especificamente estamos nos referindo aos municípios que faziam parte desta região em 1991, pois no decorrer dos anos 90 , vários distritos destes se separaram e passaram ao status administrativo de municípios. 
16 Em nossas pesquisas acerca da distribuição da população negra no Estado do Rio de Janeiro, além da baixada fluminense dois outros municípios da Região Metropolitana do Rio de Janeiro tem nos chamado a atenção: São Gonçalo e Itaboraí. Ambos, apresentam enorme aumento de população entre 1980 e 1991. Em São Gonçalo o crescimento total é de $26,72 \%$ e em Itaboraí é $42,08 \%$. Neste crescimento total, o peso da população negra é muito grande: cresce $59,17 \%$ em S. Gonçalo e $61,24 \%$ em Itaboraí (enquanto os brancos aumentam em $5,57 \%$ no primeiro e $20,98 \%$ no segundo). Assim, em 1991, em Niterói (cidade apon-

136 tada na mídia como a que possui a melhor qualidade de vida no Estado do Rio de Janeiro) a proporção de negros é de 30,58\%. Vizinha a Niterói e por muitos anos a clássica área de expansão urbana desta, São Gonçalo possui uma população negra de $49,47 \%$. E Itaboraí que se situa geograficamente logo depois de São Gonçalo e se transformou em "área de expansão II" de Niterói, tem um total de $59,76 \%$ de negros em sua população.

17 Muito embora vários destes grupos de pagode atuem como se estivessem no "Jogo do carona" e se auto-nomeiem de forma notadamente étnica, como por exemplo: "Raça Negra", "Negritude Jr.", "Raça Pura" e "Só Preto sem Preconceito". Para além disto, porém, ainda que músicos negros predominem também no pagode, o figurino utilizado em nada se associa à uma aproximação com a África (como faz o afoxé Olodum, por exemplo), ou com os negros norte americanos (como fazem os grupos de rap em geral).

18 Um exagero retórico que não desfaz a verdade inequívoca do argumento.

19 Embora a questão da discriminação racial e das relações raciais no Brasil aparecerem com muita constância, mesmo que de forma tangencial.

20 Estas chamadas "Feiras Hype" foram um grande sucesso nos bairros de classe média e média alta do Rio de Janeiro em 1999.

\section{Bibliografia}

ANDERSON, Benedict. Nação e Consciência nacional. São Paulo, Ática, 1989. 
ANDREWS, George R. Negros e Brancos em São Paulo. Bauru, EDUSC, 1998.

BHABHA, Homi K. Nation and narration. London, Routledge, 1990.

BHABHA, Homi K. O Local da Cultura. Belo Horizonte, UFMG, 1998.

BOURDIEU, Pierre. A Miséria do Mundo. Petrópolis, Vozes, 1998.

GILROY, Paul. The Black Atlantic: modernity and double consciousness. Cambridge, Havard University Press, 1995.

HASENBALG, Carlos e SILVA, Nelson do Valle. Estrutura Social, Mobilidade e Raça. Rio de Janeiro, IUPERJ/Vértice, 1988.

JORNAL FOLHA DE SÃO PAULO, anos de 1994, 1995, 1996 , 1997 e 1998.

LOVELL, Peggy. Desigualdade Racial no Brasil Contemporâneo. Belo Horizonte, UFMG / CEDEPLAR, 1991.

LOVELL, Peggy. "Raça e gênero no Brasil." In Lua Nova - Revista de Cultura e Política. CEDEC, $\mathbf{n}^{\circ}$ 35, 1995.

OLIVEIRA, Jane et all. "Mudanças no perfil de trabalho e rendimento no Brasil." In IBGE. Indicadores Sociais - uma análise da década de 1980. Rio de Janeiro, IBGE, 1995.

OLIVEIRA, Lucia Helena G. de et all. O Lugar do Negro na Força de Trabalho. Rio de Janeiro, IBGE, 1985.

PIERUCCI, Antonio F. Ciladas da Diferença. São Paulo, Editora 34, 1999.

RENAN, Ernest. "What is a nation ?" In BHABHA, Homi K. Nation and narration. London, Routledge, 1990.

SANSONE, Lívio. "A produção de uma cultura negra (da cultura "creole, à subcultura negra. A nova etnicidade negra dos jovens 'creoles' surinameses de classe baixa em amsterdam)". In Estudos Afro-Asiáticos, n² 20, junho de 1991.

SANSONE, Lívio. "Cor; classe e modernidade em duas áreas da Bahia (algumas primeiras impressões)". In Estudos Afro-Asiáticos, n $^{\circ} 23$, dezembro de 1992. 
SANSONE, Lívio. "Pai preto, filho negro: trabalho, cor e diferenças de geração." In Estudos Afro-Asiáticos, $n^{\circ} 25$, dezembro 1993.

SANSONE, Lívio. "O local e o global na afro-Bahia contemporânea". In ANPOCS, Revista Brasileira de Ciências Sociais, $n^{\circ}$ 29, outubro de 1995.

SANSONE, Lívio. "A internacionalização da cultura negra: uma comparação entre Salvador e Amsterdam". Novos Estudos CEBRAP, $\mathrm{n}^{\circ}$ 55, 1999.

138 SANT'ANNA, Wânia e PAIXÃO, Marcelo. "Desenvolvimento humano e população afro-descendente no Brasil: uma questão de raça." In Proposta, n ${ }^{0} 73$, junho/agosto de 1997.

Palavras-chave:

1. Imprensa;

2. relações raciais;

3. questão étnica;

4. essencialismo;

5. diferenças culturais. 